\title{
ANÁLISE ESPACIAL DO ESTRESSE COMPETITIVO, INCREMENTO DIAMÉTRICO E ESTRUTURA DE UMA FLORESTA OMBRÓFILA MISTA, IRATI, PR
}

\author{
Saulo Jorge Téo ${ }^{1 *}$, Afonso Figueiredo Filho ${ }^{2}$, Christel Lingnau ${ }^{3}$ \\ ${ }^{1 *}$ Universidade do Oeste de Santa Catarina, Departamento de Engenharia Florestal, Xanxerê, Santa Catarina, Brasil - \\ sauloteo@yahoo.com.br \\ ${ }^{2}$ Universidade Estadual do Centro-Oeste, Departamento de Engenharia Florestal, Irati, Paraná, Brasil - afigfilho@gmail.com \\ ${ }^{3}$ Universidade Federal do Paraná, Departamento de Ciências Florestais, Curitiba, Paraná, Brasil - lingnau @ufpr.br
}

Recebido para publicação: 20/02/2015 - Aceito para publicação: 08/06/2015

\begin{abstract}
Resumo
Um Sistema de Informações Geográficas (SIG) pode ser utilizado como ferramenta na tomada de decisões do manejo florestal, devido a sua capacidade de integrar um grande número de variáveis para gerar informações. O objetivo deste trabalho foi utilizar um SIG para representação espacial do estresse competitivo, incremento diamétrico, estrutura, ingresso e mortalidade em nível de árvore individual. A área de estudo faz parte da Floresta Nacional (FLONA) de Irati, localizada no município de Teixeira Soares e Fernandes Pinheiro, na região Centro-Sul do estado do Paraná. Os dados deste estudo provieram de parcelas permanentes em um remanescente de Floresta Ombrófila Mista mantido sem intervenção há pelo menos 65 anos. O índice de competição de melhor desempenho $I_{C 3}=d_{i} / d_{g}$, incremento diamétrico, estrutura vertical e horizontal para todas as espécies e para as principais espécies do fragmento florestal foram representados utilizando SIG, por meio de agrupamentos e consultas de dados espaciais e dos inventários florestais. A utilização de SIG permitiu a espacialização do estresse competitivo, do incremento diamétrico, dentre outras variáveis e suas combinações em nível de árvore individual. A representação espacial do incremento diamétrico das árvores apresentou relação com outras variáveis além dos índices de competição.
\end{abstract}

Palavras-chave: Sistema de informações geográficas; Índice de competição; incremento periódico.

\begin{abstract}
Spatial analysis of competitive stress, diameter increment and structure of an Araucaria forest, Irati, $P R$. A Geographic Information System (GIS) can be used as a tool in decision making for forest management due to its ability to integrate a large number of variables in order to generate information. The objective of this research was use GIS to spatial representation of competitive stress, diametric increment, structure, recruitment and mortality in individual tree level. The focused area is a fragment of the National Forest of Irati, located in districts of Teixeira Soares and Fernandes Pinheiro, in the Central-South region of Paraná State, Brazil. The data of this research came from permanent sample plots in a remaining of Araucaria Forest maintained without interventions for at least 65 years. The best performance competition index $C_{I 3}=d_{i} / d_{g}$, diametric increment, vertical and horizontal structure for all trees and for the most important species of the forest fragment were represented using GIS, through clustering and consultations of spatial data and forest inventory. The GIS tool allows the spatialization of the competitive stress, the diameter increment and other variables, as well as their combinations in individual tree level. The spatial representation of tree diametric increment presents relation with others variables besides the competition indexes.

Keywords: Geographic information system; Competition index; periodic increment.
\end{abstract}

\section{INTRODUÇÃO}

Os Sistemas de Informações Geográficas (SIGs) têm sido adotados como ferramenta de gerenciamento nas mais diversas áreas, notadamente na Ambiental, Florestal e Agrícola, devido a sua capacidade de agregar dados dispersos, de diferentes formatos e fontes, em um mesmo sistema georreferenciado, associando dados geográficos e não espaciais, e agilizando o processo de atualização e criação de mapas (DECANINI, 2001; RODRIGUES et al., 2001; OLIVEIRA FILHO et al., 2003).

FLORESTA, Curitiba, PR, v. 45, n. 4, p. 681 - 694, out. / dez. 2015.

Téo, S. J. et al.

ISSN eletrônico 1982-4688 / ISSN impresso 0015-3826

681

DOI: $10.5380 /$ rf.v45i4.39939 
Segundo Donha et al. (2006), a tecnologia SIG tem sido usada por vários setores que tratam da questão ambiental como importante ferramenta para o planejamento, pois a avaliação integrada de um grande número de variáveis se torna possível e simplificada com o uso deste sistema; permite a rápida geração de informações intermediárias e finais, além de inclusão de variáveis anteriormente não abordadas, visto que possibilita novas interações a qualquer momento.

Oliveira Filho et al. (2003) integraram o Sistema de Processamento de Informações Georreferenciadas (SPRING), desenvolvido pelo Instituto Nacional de Pesquisas Espaciais (INPE), e o Simulador de Crescimento e Produção de Pinus spp. (SISPINUS), visando à implementação completa de um SIG, em uma empresa florestal. Partindo da base cartográfica, das informações de inventários florestais, simulações de crescimento e cálculos de parâmetros econômicos os autores obtiveram diversos mapas temáticos com informações georreferenciadas de produção total por hectare, produção por sortimento, agendamento de desbaste e corte raso, valor líquido presente, taxa interna de retorno, dentre outras inúmeras informações importantes para o manejo e planejamento florestal. Certamente o trabalho de Oliveira Filho et al. (2003) foi pioneiro ao representar informações de simulação do crescimento e produção florestal e de retorno econômico, para diferentes regimes de manejo, na forma de SIG.

É tarefa do manejador decidir sobre o melhor regime de manejo para uma floresta, isto é, indicar a combinação ideal de densidade do plantio, frequência e intensidade de desbastes, comprimento de rotação, enriquecimento e supressão de espécies florestais, talhadia, dentre outros tratos silviculturais. Para avaliar qual dessas combinações será a melhor, a predição presente e futura da produção por sítio, idade e densidade do povoamento é o componente mais importante. Assim, de acordo com Scolforo (2006), sem que seja feito um forte investimento na predição presente e futura da produção florestal, as quais propiciem informações seguras e precisas, não se consegue obter planos de manejo otimizados que mantenham vínculo estreito com a realidade. Por sua vez, Oliveira Filho et al. (2003) demostraram que as informações sobre a floresta apresentadas na forma de SIG constituem uma ferramenta muito poderosa para o processo de tomada de decisões e planejamento florestal.

O comportamento e evolução de florestas podem ser mais bem compreendidos quando estudados em nível de indivíduo, como por exemplo, sua sobrevivência e crescimento individual. Isto porque a imobilidade e a plasticidade fenotípica das plantas fazem com que as variações locais sejam extremamente importantes na determinação de sua sobrevivência, crescimento, floração e frutificação. A interferência dos vizinhos pode ser um dos fatores mais importantes da variação local (WEINER, 1984).

A competição unilateral é uma tentativa de descrever a posição sociológica de uma árvore em um povoamento e quantificar a competitividade do ambiente a sua volta. Consequentemente, os índices de competição unilaterais são, frequentemente, únicos para cada indivíduo em um povoamento. Existem numerosos índices de competição unilaterais, tanto dependentes como independentes da distância (WEISKITTEL et al., 2011).

Os índices de competição, ou índices de densidade pontuais, podem ser tratados como dependentes da distância ou independentes da distância. Os independentes da distância consideram que a competição não é avaliada pela localização da árvore objeto com relação às suas vizinhas, já os dependentes da distância usam mapeamento das árvores em uma parcela para determinar a competição (DAVIS et al., 2001).

Além de expressarem o estresse competitivo de cada indivíduo da floresta, os índices de competição constituem o centro de todo modelo de crescimento de árvore individual, onde é utilizado para determinar o crescimento e mortalidade durante a simulação. Este índice deve quantificar a habilidade competitiva, experimentada por uma árvore e, na maioria dos casos, é considerado para representar o efeito total da competição por recursos escassos, como luz, água, nutrientes e espaço físico (DANIELS; BURKHART, 1975).

Na literatura, existem diversas alternativas de índices de competição independentes da distância (PRODAN et al., 1997; DAVIS et al., 2001), os quais geralmente comparam as dimensões da árvore objeto, ou seja, da árvore para o qual se deseja calcular o estresse competitivo, com as dimensões das demais árvores do povoamento. Martins et al. (2011) avaliaram cinco índices de competição independentes da distância, para plantios comerciais de eucalipto, quanto às suas qualidades para expressar a probabilidade de mortalidade e o crescimento, tanto em diâmetro como em altura.

Este trabalho visa calcular índices de competição independentes da distância para dados de censo florestal de um fragmento de Floresta Ombrófila Mista, em Irati, PR, e representa-los na forma de Sistema de Informações Geográficas para espacialização do estresse competitivo e de sua relação com o incremento 
diamétrico, estrutura horizontal e vertical, ingresso, mortalidade de todas as árvores da floresta e a distribuição espacial e horizontal da araucária (Araucaria angustifolia (Bertol.) Kuntze), sassafrás (Ocotea odorifera (Vellozo) Rohwer), canela-amarela (Nectandra grandiflora Nees \& C. Mart. ex Nees), imbuia (Ocotea porosa (Nees \& C. Mart.) Barroso) e erva-mate (Ilex paraguariensis A. St.-Hil).

\section{MATERIAL E MÉTODOS}

A área de estudo faz parte da Floresta Nacional (FLONA) de Irati (Figura 1), a qual originou-se da necessidade de pesquisar a Araucaria angustifolia, sob diferentes regimes de manejo, criada pela Portaria do Instituto Brasileiro de Desenvolvimento Florestal (IBDF) n ${ }^{\circ} 559$, de 25 de outubro de 1968. A FLONA de Irati localiza-se no município de Teixeira Soares e Fernandes Pinheiro, na região Centro-Sul do estado do Paraná e possui área de 3.495 ha, composta por Floresta Ombrófila Mista e povoamentos de Araucaria angustifolia e Pinus sp.

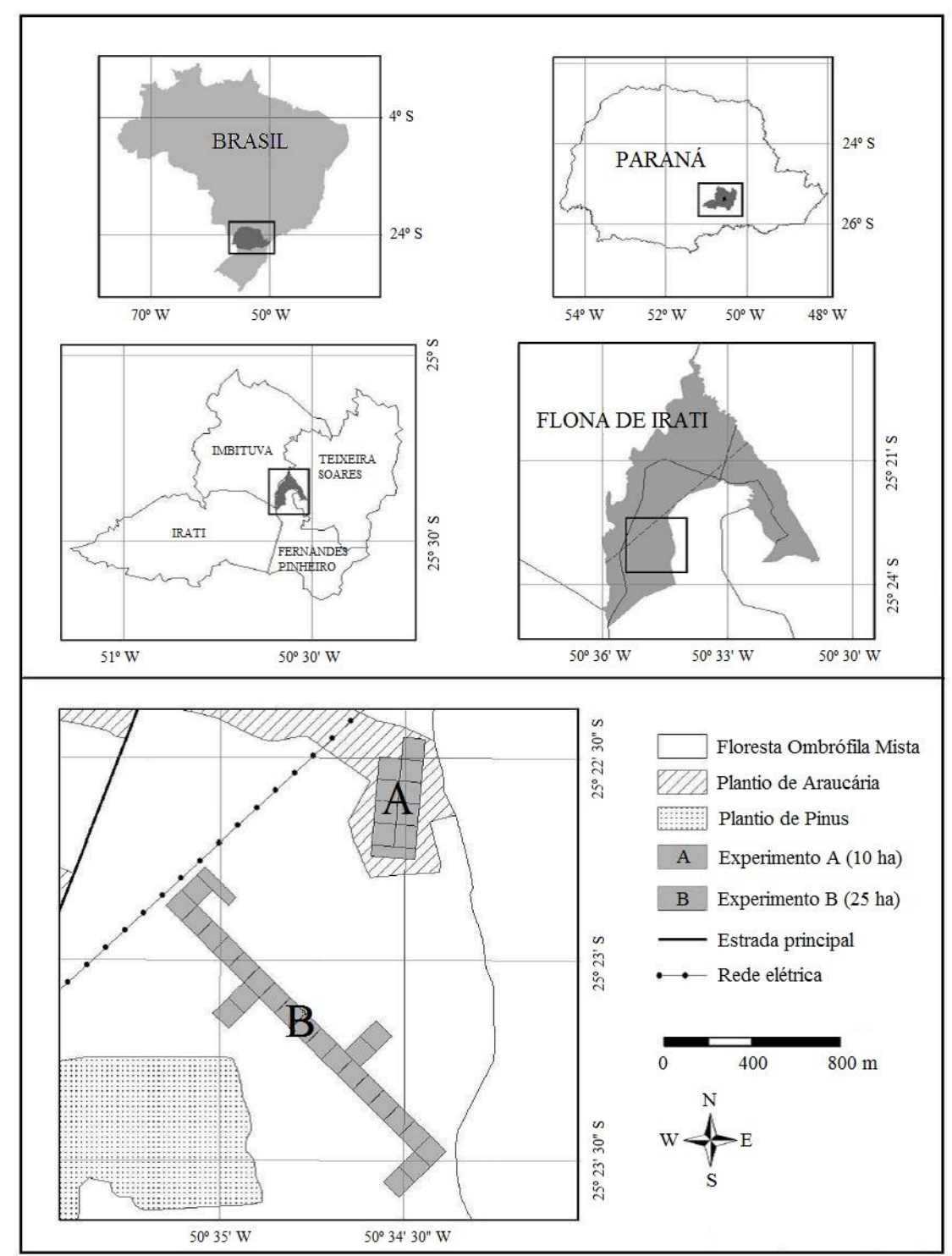

Figura 1. Localização da FLONA de Irati, estado do Paraná, Brasil. Figure 1. Location of the Irati National Forest, Paraná State, Brazil. Fonte: Rode et al. (2010).

FLORESTA, Curitiba, PR, v. 45, n. 4, p. 681 - 694, out. / dez. 2015. 
Antes de sua criação pelo IBDF, a FLONA de Irati era conhecida como Parque Florestal e pertencia ao extinto Instituto Nacional do Pinho, criado com o objetivo de coordenar trabalhos relativos à defesa da produção do Pinho (Araucaria angustifolia).

A região de estudo localiza-se no segundo planalto paranaense, caracterizada geologicamente por cobertura sedimentar originária no oceano Pantalassa, o qual recobriu grande extensão da América do Sul (KERSTEN et al., 2008). Pertence à zona climática Temperada, do tipo Mesotérmico brando (temperatura média entre 10 e $15{ }^{\circ} \mathrm{C}$ ), Superúmido sem seca (IBGE, 2010 a). A cobertura vegetal primária da região de estudo é a Floresta Ombrófila Mista, a qual nos padrões florestais melhor desenvolvidos distingue-se, logo abaixo da copagem da araucária, um estrato contínuo constituído de elementos latifoliados, onde além da Araucaria angustifolia, pode-se citar como espécies características, o Podocarpus lambertii Klotz., Drimys brasiliensis Miers, Nectandra grandiflora Ness, Ilex paraguariensis St. Hil., Cupania vernalis Camb., Matayba elaeagnoides Radlk., Capsicodendron dinisii Schwancke, Campomanesia xanthocarpa Berg., dentre várias outras mirtáceas e aquifoliáceas (IBGE, 2010 b; LEITE, 2002). Os principais tipos de solos são CAMBISSOLOS HÁPLICOS Alumínicos, CAMBISSOLOS HÚMICOS Alumínicos e LATOSSOLOS VERMELHOS Distróficos (EMBRAPA, 2007).

Os dados deste estudo provieram de parcelas permanentes do Experimento B (Figura 1), instaladas com teodolito nos anos de 2000/2001 em um remanescente de Floresta Ombrófila Mista com $1.272,90$ ha, mantido sem intervenção há pelo menos 65 anos. Foram estabelecidos 25 blocos contínuos de 1 ha, com dimensões de 100 x $100 \mathrm{~m}$. Cada bloco foi dividido em parcelas com 0,25 ha $(50 \times 50 \mathrm{~m})$, as quais, para facilitar a numeração e mapeamento das árvores, foram ainda subdivididas em 5 faixas de controle (subparcelas) de 0,05 ha $(10 \times 50 \mathrm{~m})$. Em 2002, todos os indivíduos arbóreos com diâmetros à altura do peito acima de $10 \mathrm{~cm}$ foram medidos, numerados, identificados (Sistema de Classificação Botânica APG II) e posicionados em um sistema de coordenadas locais (X,Y) (FIGUEIREDO FILHO et al., 2010). As remedições ocorreram em intervalos de 3 anos, das quais as de 2005 e 2008 constituem a base de dados deste trabalho.

Para expressar a competição ou densidade pontual das árvores, foram calculados diversos índices de competição independentes da distância, os quais foram apresentados por Prodan et al. (1997), Davis et al. (2001) e Martins (2011). Estes índices de competição foram calculados para a medição realizada em 2005.

$$
\begin{gathered}
I_{C 1}=\frac{d_{i}}{\bar{d}} ; I_{C 2}=\frac{d_{i}^{2}}{\bar{d}^{2}} ; I_{C 3}=\frac{d_{i}}{d_{g}} ; I_{C 4}=\frac{d_{i}^{2}}{d_{g}^{2}} ; I_{C 5}=\frac{d_{i}}{d_{\text {máx }}} \\
I_{C 6}=\frac{d_{i}^{2}}{d_{\text {máx }}^{2}} ; I_{C 7}=\frac{d_{i}}{d_{d o m}} ; I_{C 8}=\frac{d_{i}^{2}}{d_{d o m}^{2}} ; I_{C 9}=\sum_{k=1}^{m} g_{k} ; I_{C 10}=\sum_{j=1}^{n} \frac{d_{j}}{d_{i}}
\end{gathered}
$$

em que: $I_{C}=$ índice de competição; $d_{i}=$ diâmetro à altura do peito da árvore objeto " $i$ " $(\mathrm{cm}) ; \bar{d}=$ diâmetro à altura do peito médio da parcela da árvore objeto " $i$ " $(\mathrm{cm}) ; d_{g}=$ diâmetro médio quadrático da parcela da árvore objeto " $i$ " $(\mathrm{cm}) ; d_{m a ́ x}=$ diâmetro máximo da parcela da árvore objeto " $i$ " $(\mathrm{cm})$; $d_{d o m}=$ diâmetro dominante da parcela da árvore objeto " $i "(\mathrm{~cm}) ; g_{k}=$ área transversal da árvore " $k$ " maior do que a árvore objeto " $i$ " $\left(\mathrm{m}^{2}\right) ; d_{j}=$ diâmetro à altura do peito da árvore competidora " $j$ " $(\mathrm{cm})$; $m=$ número de árvores com diâmetro maior do que a árvore objeto " $i$ ", da parcela da árvore objeto " $i$ "; $n=$ número de árvore competidoras, da parcela da árvore objeto " $i$ ".

A avaliação dos índices de competição foi feita por meio do cálculo do seu coeficiente de correlação com o incremento periódico em diâmetro das árvores $\left(I P_{d}\right)$, entre as remedições de 2005 e 2008. Os incrementos negativos foram desconsiderados.

$$
I P_{d}=d_{2008}-d_{2005}
$$

em que: $I P_{d}=$ incremento periódico em diâmetro; $d_{2008}=$ diâmetro à altura do peito em $2008(\mathrm{~cm})$; $d_{2005}=$ diâmetro à altura do peito em $2005(\mathrm{~cm})$. 
Após a avaliação dos índices de competição, aquele de melhor desempenho foi selecionado para representação espacial do estresse competitivo das árvores da FLONA de Irati, bem como, sua relação com o incremento diamétrico, ingresso, mortalidade, estrutura horizontal e vertical.

Os dados espaciais foram orientados aos objetos blocos e árvores, onde os blocos foram representados por polígonos (área de $1 \mathrm{ha}$ ) e as árvores por entidades pontuais, conforme sistema de coordenadas locais $(\mathrm{X}, \mathrm{Y})$. Para permitir a espacialização das variáveis envolvidas, foram feitos agrupamentos e consultas com os dados espaciais, com os dados dos inventários florestais de 2005 e 2008 da FLONA de Irati e cálculos realizados especificamente para este estudo, detalhados anteriormente. No aplicativo computacional ArcGIS 10.1, foram definidas 10 classes de competição e incremento. Já a classificação diamétrica tanto de todos os indivíduos da floresta, como separadamente das espécies de maior ocorrência da FLONA de Irati araucária (Araucaria angustifolia), sassafrás (Ocotea odorifera), canela-amarela (Nectandra grandiflora), imbuia (Ocotea porosa) e erva-mate (Ilex paraguariensis) foi realizada com intervalo de classe absoluto de $10 \mathrm{~cm}$.

\section{RESULTADOS E DISCUSSÃO}

De acordo com os coeficientes de correlação dos diferentes índices de competição com o incremento diamétrico das árvores, do período entre 2005 e 2008, o $I_{C 3}$ apresentou o maior valor, seguido do $I_{C 5}, I_{C 7}$ e do $I_{C 1}$. Estes índices foram compostos pelo quociente entre o diâmetro da árvore objeto pelo diâmetro médio quadrático, diâmetro máximo, diâmetro dominante e diâmetro médio, respectivamente. As formas quadráticas desses índices $\left(I_{C 2}, I_{C 4}, I_{C 6}\right.$ e $\left.I_{C 8}\right)$ apresentaram coeficientes de correlação inferiores às suas formas lineares. Enquanto que os índices $I_{C 9}$ e $I_{C 10}$ apresentaram os menores valores de coeficientes de correlação com o incremento diamétrico (Tabela 1).

Tabela 1. Coeficiente de correlação entre os índices de competição e o incremento diamétrico das árvores de um fragmento de Floresta Ombrófila Mista, Irati, Paraná.

Table 1. Correlation coefficient of de competition index and diameter increment of the trees in a fragment of Araucaria Forest, Irati, Paraná State, Brazil.

\begin{tabular}{cc}
\hline \multicolumn{2}{c}{ Coeficiente de correlação } \\
\hline$I_{C 1}$ & 0,408038 \\
$I_{C 2}$ & 0,337500 \\
$I_{C 3}$ & 0,414129 \\
$I_{C 4}$ & 0,343993 \\
$I_{C 5}$ & 0,414101 \\
$I_{C 6}$ & 0,343681 \\
$I_{C 7}$ & 0,412440 \\
$I_{C 8}$ & 0,340216 \\
$I_{C 9}$ & $-0,079671$ \\
$I_{C 10}$ & $-0,114193$ \\
\hline
\end{tabular}

De acordo com os coeficientes de correlação (Tabela 1), quanto maior os valores dos índices de competição maior é a capacidade de crescimento das árvores. Esta tendência foi verificada para os índices $I_{C 1}$ até $I_{C 8}$, porém o contrário pode ser verificado para $I_{C 9}$ e $I_{C 10}$, os quais apresentaram valores de coeficientes de correlação negativos.

Chassot et al. (2011) encontraram coeficientes de correlação inferiores aos encontrados neste estudo, entre diferentes índices de competição e o incremento diamétrico de Araucaria angustifolia, em área de Floresta Ombrófila Mista, na FLONA de São Francisco de Paula, estado do Rio Grande do Sul. O valor mais acentuado de coeficiente de correlação foi de $-0,23$, entre o incremento diamétrico de Araucária e o $I_{C 9}$, indicando que quanto menores os valores deste índice, maior será o incremento em diâmetro. De maneira geral, constatou-se que os índices de competição não mostraram eficiência para explicar o crescimento dos indivíduos de Araucaria angustifolia.

Por outro lado, Della-Flora et al. (2004) estudaram o efeito de diferentes variáveis sobre o incremento corrente anual de indivíduos de Nectandra megapotamica (Spreng.) Mez, em São João do

FLORESTA, Curitiba, PR, v. 45, n. 4, p. 681 - 694, out. / dez. 2015.

Téo, S. J. et al.

ISSN eletrônico 1982-4688 / ISSN impresso 0015-3826

DOI: $10.5380 /$ rf.v45i4.39939 
Polêsine, Rio Grande do Sul, destacando que os modelos de melhor ajuste apresentavam como variável independente o $I_{C 9}$, o qual expressou melhor a concorrência quando comparado com a área basal por hectare.

Orellana (2014) desenvolveu um modelo de árvore individual para a FLONA de Irati, em que o $I_{C 9}$ foi utilizado para expressar a competição entre as árvores, principalmente a competição por luz. Embora Orellana (2014) não tenha testado outros índices de competição independentes da distância, sua análise permitiu um diagnóstico da competição de maneira mais detalhada, pois as árvores foram separadas por grupos de espécies, os quais foram: Estrato Inferior, Sub-bosque, Umbrófilas do Dossel, Heliófilas do Dossel, Pioneiras e Emergentes. Assim, foi verificado o efeito mais acentuado do índice de competição sobre as Pioneiras e Emergentes, quando comparado ao efeito sobre aquelas do Sub-bosque e Umbrófilas, mais habituadas à sombra e menos exigentes quanto à intensidade de luz.

A figura 2 ilustra a identificação e organização dos blocos da FLONA de Irati, bem como sua estrutura horizontal e vertical, onde foram utilizadas classes diamétricas absolutas, com intervalo de 10 $\mathrm{cm}$ e a definição dos diferentes estratos ocupados pelos indivíduos, em Sub-bosque, Estrato Intermediário e Dossel.

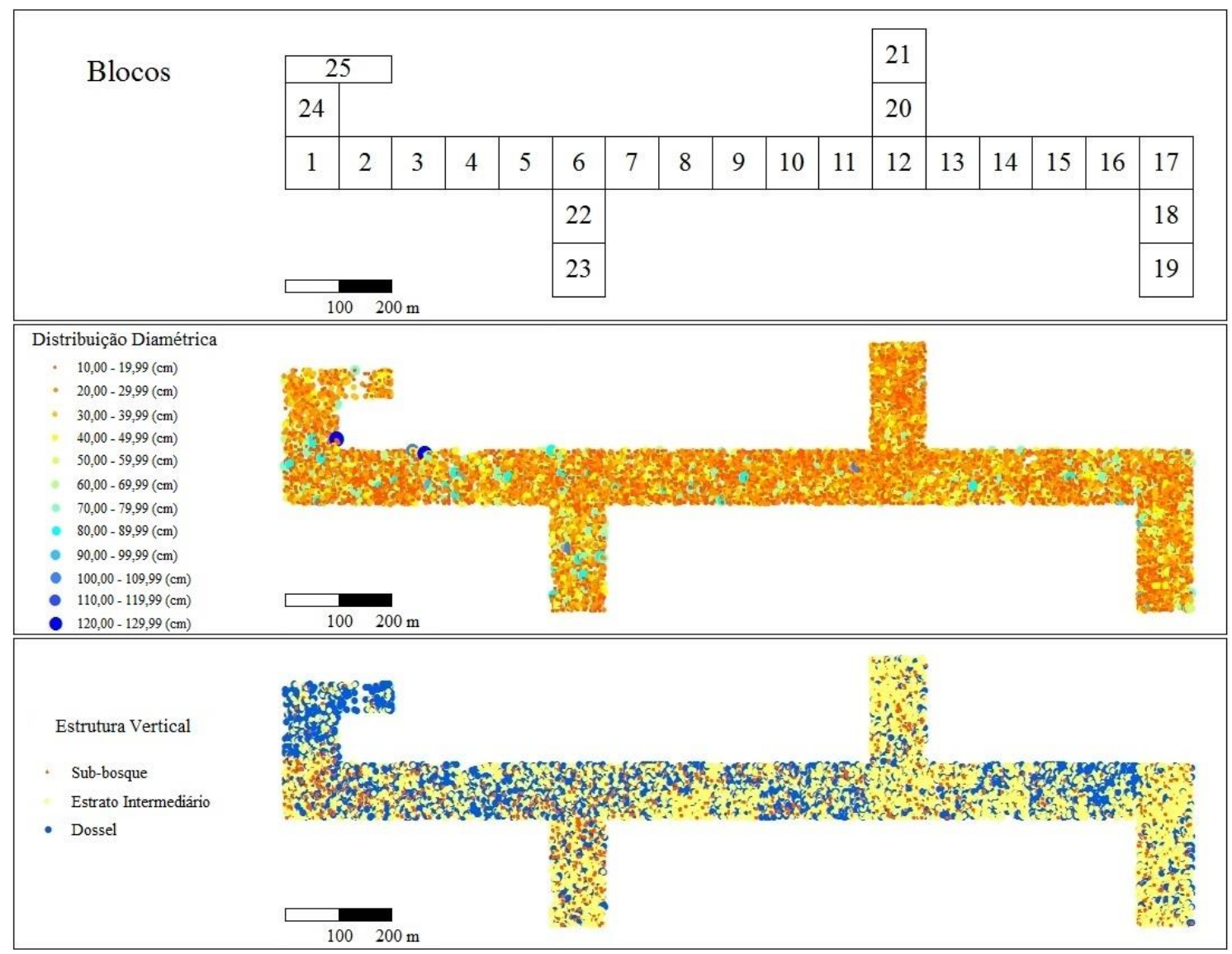

Figura 2. Identificação dos Blocos, distribuição diamétrica e estrutura vertical de cada árvore da FLONA de Irati, Paraná.

Figure 2. Blocks identification, diameter distribution and vertical structure of each tree of the Irati National Forest, Paraná State, Brazil.

A grande maioria das cerca de 15 mil árvores medidas na FLONA de Irati apresentam diâmetros de até $30 \mathrm{~cm}$, com alguns poucos indivíduos acima de $60 \mathrm{~cm}$ de diâmetro, caracterizando uma distribuição decrescente ou em formato de J-invertido, conforme constatado por Figueiredo Filho et al. 
(2010), típico da estrutura diamétrica das florestas mistas. É possível verificar que as árvores com mais de $120 \mathrm{~cm}$ de diâmetro à altura do peito se encontram nos blocos 3 e 24 (Figura 2).

Quanto à estrutura vertical, a distribuição entre dossel, estrato intermediário e sub-bosque é mais uniforme, contudo é possível identificar algumas áreas com predominância de árvores no dossel, como os blocos 24 e 25 e outras com predominância de árvores no estrato intermediário e sub-bosque, nos blocos $1,8,12,13,17,18,19$ e 21 (Figura 2).

A figura 3 apresenta a classificação quanto à área basal, estresse competitivo, incremento periódico em diâmetro. A área basal da FLONA de Irati variou de 15,07 até 35,60 m²/ha, para o bloco 25 e 19, respectivamente. Os blocos 17, 18 e 19 apresentaram valores muito próximos de área basal, 35,43; 35,02 e $35,60 \mathrm{~m}^{2} / \mathrm{ha}$, respectivamente.

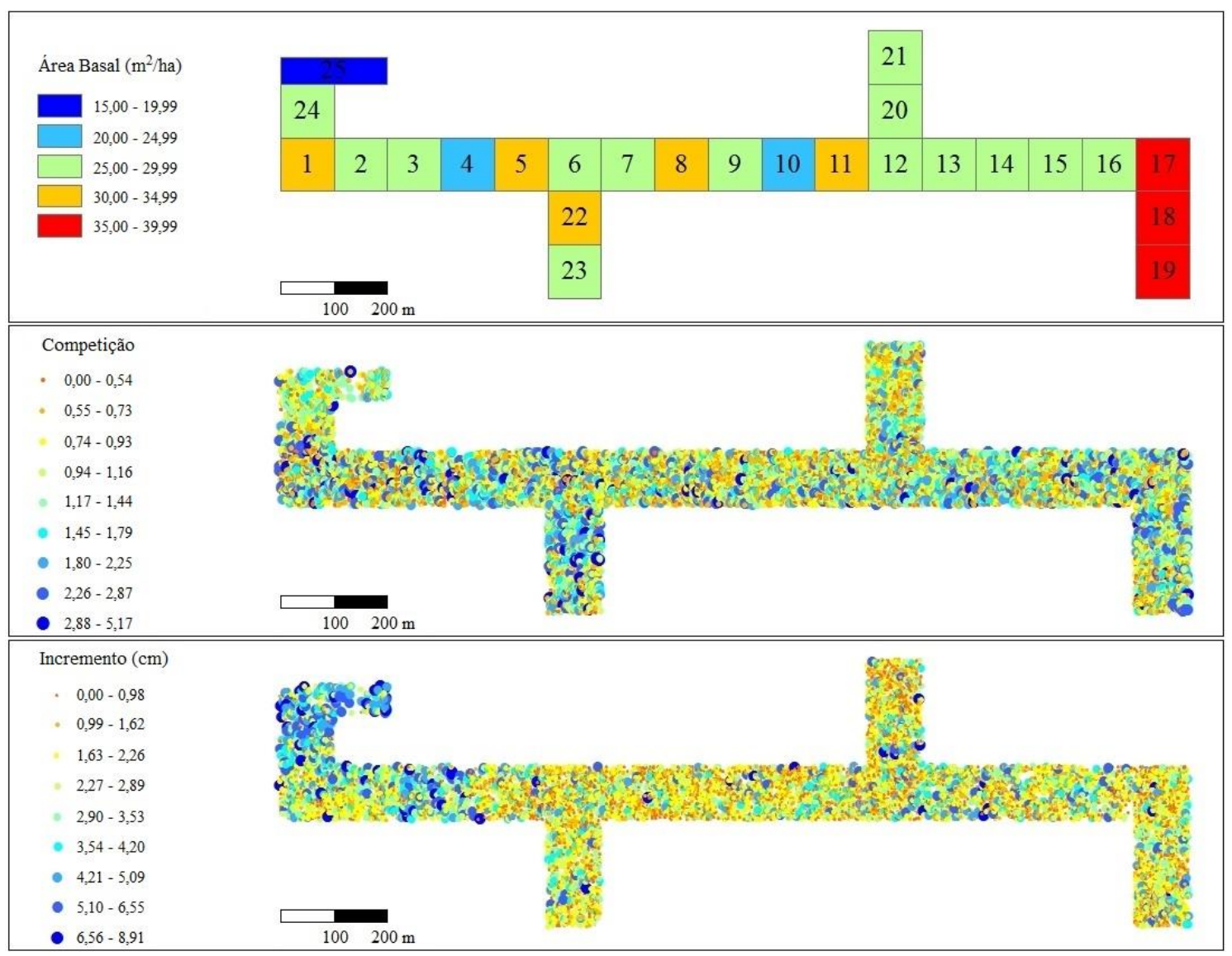

Figura 3. Identificação dos Blocos, área basal, competição $\left(I_{C 3}\right)$, incremento diamétrico $\left(I P_{d}\right)$ de cada árvore da FLONA de Irati, Paraná.

Figure 3. Blocks identification, basal area, competition $\left(I_{C 3}\right)$, diameter increment $\left(I P_{d}\right)$ of each tree of the Irati National Forest, Paraná State, Brazil.

Por toda a área da FLONA de Irati, ocorreram árvores com valores altos e baixos de $I_{C 3}$, indicando pequeno e grande estresse competitivo, respectivamente. Com esforço, nota-se uma concentração de árvores com baixos valores de $I_{C 3}$ no bloco 21, valores intermediários nos blocos 24 e 25 e valores altos nos blocos 3, 4 e 22 (Figura 3).

Por outro lado, quando o incremento periódico em diâmetro $\left(I P_{d}\right)$ é analisado, notam-se grandes valores para os blocos 3, 4 e principalmente para os blocos 24 e 25, também para os blocos 13 e 14, porém com menor frequência. Já uma maior concentração de árvores com valores baixos de $I P_{d}$ são observados para os blocos 8, 17, 18, 19 e 21 (Figura 3). 
Como apresentado na tabela 1 , o coeficiente de correlação entre o estresse competitivo $\left(I_{C 3}\right)$ e o incremento diamétrico $\left(I P_{d}\right)$ não alcançou valor muito alto, então nem sempre os blocos que apresentaram concentração de árvores com menor estresse competitivo apresentaram os maiores incrementos diamétricos.

Os índices de competição apresentados na tabela 1 expressam a competição unilateral, onde as maiores árvores não são afetadas pelas menores, sendo um bom indicativo da competição por luz. No entanto, a competição bilateral considera que todos os demais recursos (água, nutrientes etc.), exceto luz, são divididos igualmente ou proporcionais ao tamanho das árvores. Enquanto os índices de competição expressam melhor a competição unilateral, a área basal pode ser utilizada para expressar a competição bilateral (BOTKIN et al., 1972; WEISKITTEL et al., 2011).

Ao ajustar modelos de incremento corrente anual de Nectandra megapotamica, Della-Flora et al. (2004) além da competição $\left(I_{C 9}\right)$, incluíram variáveis para expressar as dimensões da árvore no início do período de crescimento, a área basal, a pedregosidade do solo e a posição sociológica de cada árvore. Orellana (2014) utilizou o diâmetro no início do período de crescimento, o índice de competição $I_{C 9}$ e a área basal para modelar o incremento em diâmetro por grupo de espécies, na FLONA de Irati. De acordo com Roik (2012), as variáveis mais correlacionadas com o incremento em diâmetro das árvores da FLONA de Irati foram a forma da copa, a posição da copa, área basal da parcela, área basal da espécie e posição sociológica.

Ao analisar a figura 3, verifica-se uma grande concentração de árvores com valores altos de incremento diamétrico $\left(I P_{d}\right)$ no bloco 25 , o qual apresentou a menor área basal, portanto menor competição bilateral. O oposto pode ser observado para os blocos 17,18 e 19, com os valores mais elevados de área basal e grande frequência de árvores com valores baixos de $I P_{d}$. O valor alto de área basal do bloco 22 pode explicar o fato de que, mesmo sem apresentar grande quantidade de árvores sofrendo grande competição por luz, apresentou, de maneira geral, valores baixos de crescimento.

O bloco 21 apresentou valor de área basal intermediário, porém suas árvores apresentaram valores baixos de $I_{C 3}$ e grande proporção das árvores no estrato intermediário e sub-bosque, o que pode evidenciar o efeito da posição sociológica sobre o incremento em diâmetro $\left(I P_{d}\right)$, como constatado por Della-Flora et al. (2004) e Roik (2012).

De maneira geral, o ingresso no período de 2005 a 2008 apresenta-se bem distribuído pela área da FLONA de Irati, entretanto é possível observar pouca ocorrência de ingresso, principalmente nos blocos 24 e 25. Quanto à mortalidade, também observa-se homogeneidade na distribuição pela área da FLONA de Irati, exceto nos blocos 17 e 18, com concentrações de ocorrência de mortalidade (Figura 4).

Ao todo, houve ingresso de 1.181 indivíduos e mortalidade de 1.520 indivíduos, no período estudado. Considerando que a população analisada consiste em aproximadamente 15 mil árvores, estes resultados coincidem com os de Figueiredo Filho et al. (2010), que encontraram ingresso e mortalidade entre 1 e 2\%, para a FLONA de Irati entre os anos de 2002 e 2008, com mortalidade maior do que o ingresso.

Conforme Botkin et al. (1972), a cada ano, novas mudas de uma determinada espécie ingressam na floresta com base em sua tolerância à sombra e se as condições climáticas e edáficas permitem o desenvolvimento desta espécie, bem como seu banco de sementes.

Para Orellana (2014), o modelo para representar o ingresso dependeu exclusivamente da área basal do grupo de espécies com relação à área basal da parcela, onde houve tendência de aumento do recrutamento com o a área basal da floresta, para os grupos de espécies tolerantes à sombra e o oposto para as espécies pioneiras. Observa-se na figura 4, poucas árvores recrutadas nos blocos 24 e 25 e grande quantidade de árvores recrutadas nos blocos 1 e 17, os quais apresentam baixos e altos valores de área basal, respectivamente. Todavia, nos demais blocos é difícil detectar diferenças na quantidade de árvores recrutadas.

Tanto Martins et al. (2011) trabalhando com Eucalyptus sp., como Orellana (2014) para as árvores da FLONA de Irati, utilizaram o diâmetro à altura do peito no início do período de medição, a área basal e o índice de competição para estimar a probabilidade de mortalidade das árvores. De acordo com Orellana (2014), houve aumento da mortalidade com a área basal, para a maioria dos grupos de espécies, principalmente para aquelas dos estratos inferiores. Já, quando analisada a tendência de mortalidade com relação ao índice de competição, há aumento da mortalidade para espécies pioneiras e tolerantes à sombra com maior estresse competitivo. 
$\mathrm{Na}$ figura 4, é possível verificar manchas de mortalidade nos blocos 17 e 18 , os quais apresentaram os maiores valores de área basal e no bloco 21, o qual apresentou baixos valores de $I_{C 3}$, indicando grande estresse competitivo. Tanto os blocos 17 e 18, como o bloco 21, apresentaram valores baixos de incremento em diâmetro $\left(I P_{d}\right)$.

A figura 5 mostra a distribuição espacial e diamétrica das principais espécies da FLONA de Irati, dentre elas a Araucaria angustifolia é a espécie que apresenta a maior quantidade de árvores de grandes diâmetros, entre 40 e $80 \mathrm{~cm}$, porém sem deixar de apresentar árvores menores. Figueiredo Filho et al. (2010) descreveram a distribuição diamétrica da Araucaria angustifolia na FLONA de Irati como multimodal, o que indicaria a possibilidade de ter ocorrido, no passado cortes seletivos da espécie em algumas classes diamétricas. Souza et al. (2008) também caracterizaram uma população de Araucaria angustifolia em Floresta Ombrófila Mista sem intervenções antrópicas, na FLONA de São Francisco de Paula, Rio Grande do Sul, com muitos indivíduos de grande porte e indivíduos pequenos relativamente raros.

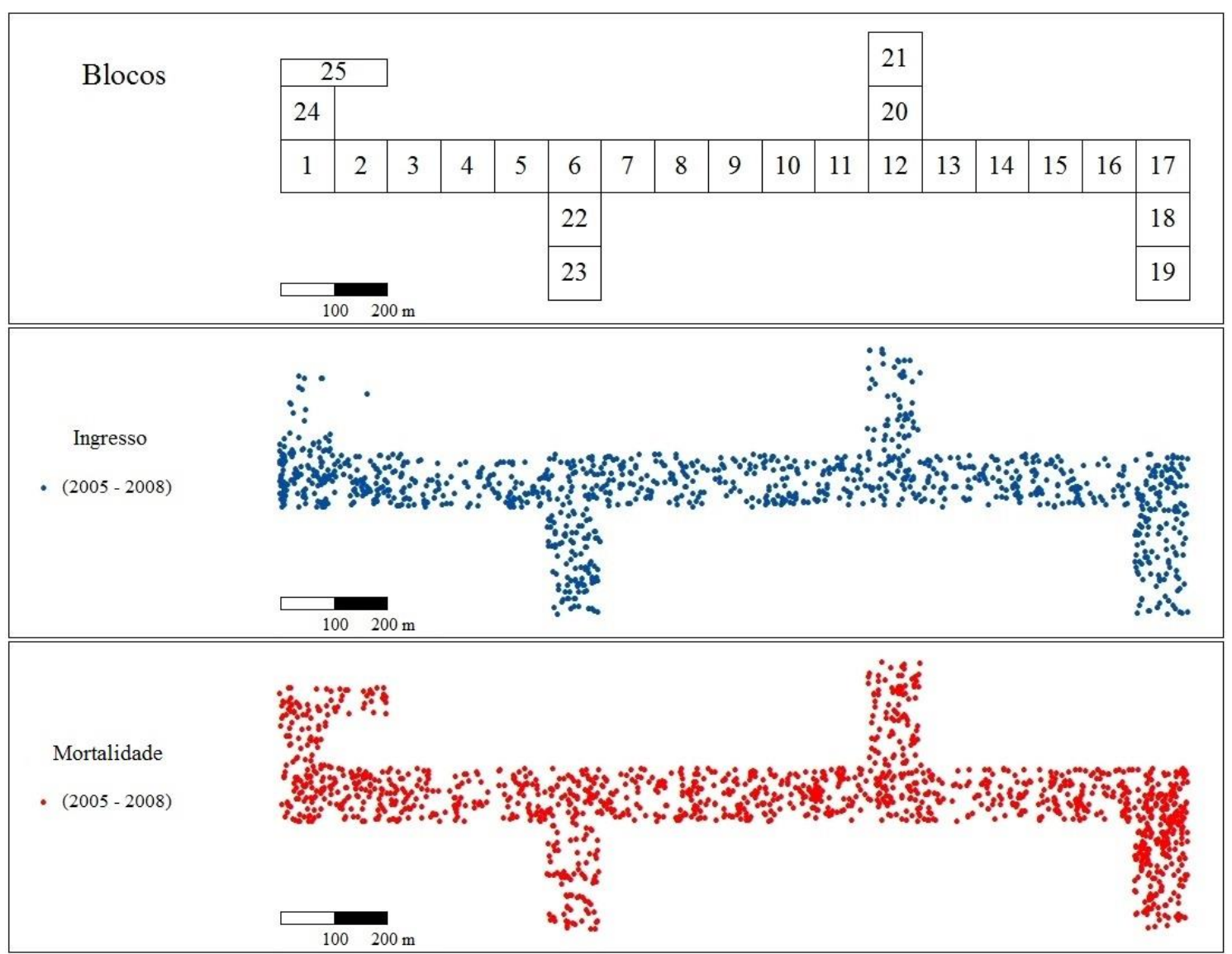

Figura 4. Identificação dos Blocos, ingresso e mortalidade em nível de árvore individual, na FLONA de Irati, Paraná.

Figure 4. Blocks identification, recruitment, and mortality in individual tree level, in the Irati National Forest, Paraná State, Brazil.

A distribuição espacial da Araucaria angustifolia na área de estudo é bastante homogênea por todos os blocos, mas com expressivo número de indivíduos de pequeno diâmetro nos blocos 3 e 19. Rode et al. (2010) encontraram padrão espacial aleatório para Araucaria angustifolia nos blocos 1 e 13 da FLONA de Irati, entretanto com picos de agregação entre 20 e $35 \mathrm{~m}$ para o bloco 1.

Além da exploração seletiva no passado, outra possível explicação para a estrutura diamétrica e espacial da Araucaria angustifolia é o modelo de regeneração estruturado em coortes. De acordo com

FLORESTA, Curitiba, PR, v. 45, n. 4, p. 681 - 694, out. / dez. 2015.

Téo, S. J. et al.

ISSN eletrônico 1982-4688 / ISSN impresso 0015-3826

DOI: $10.5380 /$ rf.v45i4.39939 
este modelo, coortes de coníferas de grande porte e exigentes em luz se estabelecem após severos distúrbios. Elas são seguidas por coortes sucessivas de espécies de angiospermas menores, que dominam o sub-bosque e reprimem o recrutamento das mudas de conífera, o qual passa a ser restrito a múltiplas clareiras provocadas pela queda de árvores. Devido ao grande porte e longevidade das coníferas adultas, sua população permanece como componente dominante da biomassa e estrutura da floresta por longos períodos de tempo (frequentemente séculos), embora funcionando como populações remanescentes com carência significativa de regeneração constante (SOUZA et al., 2008).

A distribuição diamétrica da Ilex paraguariensis apresentou os menores valores com relação às demais espécies analisadas, conforme Figueiredo Filho et al. (2010), apresenta distribuição diamétrica marcadamente decrescente (J-invertido). Quanto à distribuição espacial, nota-se a distribuição homogênea por todos os blocos da FLONA de Irati, tanto de indivíduos com menores e maiores diâmetros. Rode et al. (2010) destacaram a distribuição espacial com grande plasticidade da Ilex paraguariensis, se comportando na maioria das vezes, de forma agrupada e com dependência espacial (atração) com a Araucaria angustifolia e Nectandra grandiflora (Figura 5).

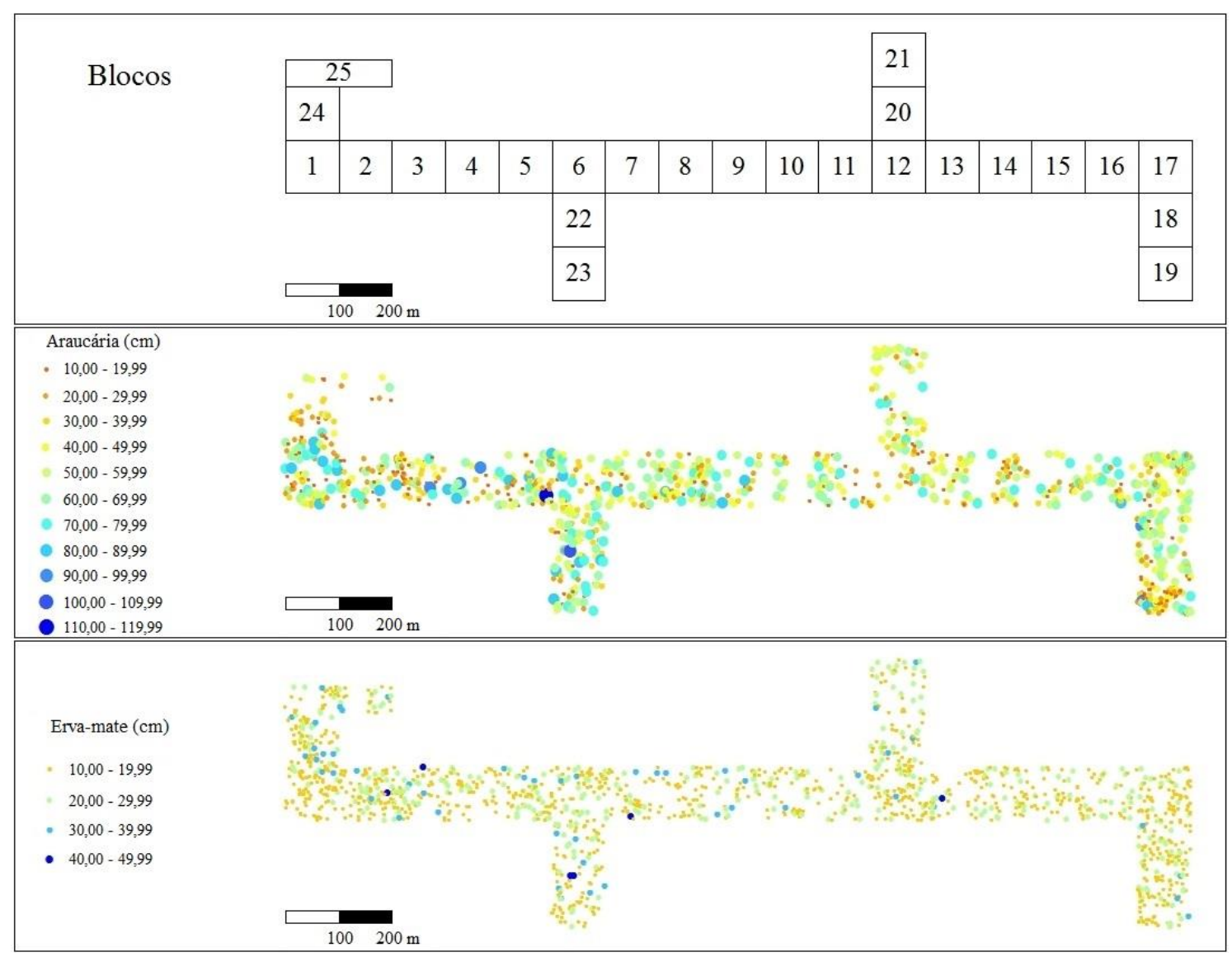

Figura 5. Identificação dos Blocos, distribuição espacial e diamétrica de araucária (Araucaria angustifolia (Bertol.) Kuntze) e erva-mate (Ilex paraguariensis A. St.-Hil.), na FLONA de Irati, Paraná.

Figure 5. Blocks identification, spatial and diameter distribution of Araucaria angustifolia (Bertol.) Kuntze and Ilex paraguariensis A. St.-Hil., in the Irati National Forest, Paraná State, Brazil.

A Ocotea odorifera apresentou grande número de indivíduos de pequeno porte, condição típica de espécies com distribuição diamétrica decrescente, conforme descrito por Figueiredo Filho et al. (2010). Quanto à distribuição espacial, há grande número de indivíduos nos blocos 7, 8, 9, 10, 11, 20 e 
21, principalmente com diâmetros de 10 a $30 \mathrm{~cm}$ e quase ausência de indivíduos de Ocotea odorifera nos blocos 1, 3, 24 e 25 (Figura 6).

A distribuição diamétrica da Nectandra grandiflora também apresenta-se com grande número de indivíduos de pequeno porte, proporcionando distribuição diamétrica decrescente (FIGUEIREDO FILHO et al., 2010), porém a quantidade de indivíduos com maiores diâmetros é mais expressiva quando comparada à espécie Ocotea odorifera. A distribuição espacial é relativamente homogênea, contudo há maior ocorrência nos blocos 1, 2, 14, 17, 18 e 19 (Figura 6).

A Ocotea porosa apresenta os indivíduos de maior diâmetro de toda a FLONA de Irati com diâmetros superiores a $120 \mathrm{~cm}$. Devido à menor proporção de indivíduos de pequeno porte a sua distribuição diamétrica é unimodal, onde as maiores frequências ocorrem nas classes de 35 e $45 \mathrm{~cm}$ de diâmetro à altura do peito (FIGUEIREDO FILHO et al., 2010). Os blocos 5, 6, 22 e 24 apresentam as maiores quantidades de indivíduos de pequeno e médio porte de Ocotea porosa (Figura 6).

Segundo Figueiredo Filho et al. (2010) e Roik (2012), as espécies que apresentam os valores mais expressivos de incremento diamétrico $\left(I P_{d}\right)$ foram a Araucaria angustifolia e Ocotea porosa, as quais possuem alguns indivíduos entre os de maiores diâmetros e, consequentemente, menor estresse competitivo.

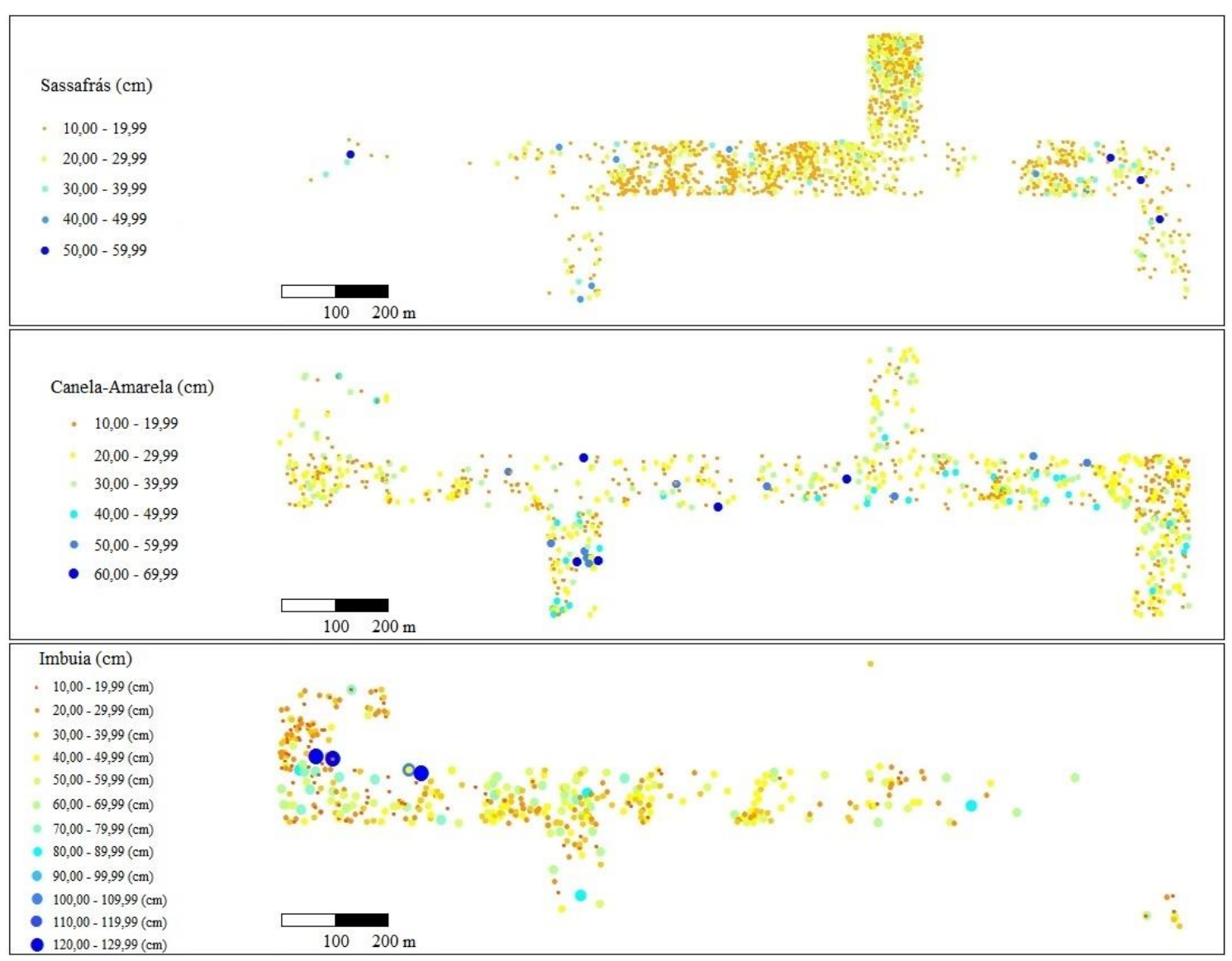

Figura 6. Distribuição espacial e diamétrica de sassafrás (Ocotea odorifera (Vellozo) Rohwer), canelaamarela (Nectandra grandiflora Nees \& C. Mart. ex Nees) e imbuia (Ocotea porosa (Nees \& C. Mart.) Barroso), na FLONA de Irati, Paraná.

Figure 6. Spatial and diameter distribution of Ocotea odorifera (Vellozo) Rohwer, Nectandra grandiflora Nees \& C. Mart. ex Nees and Ocotea porosa (Nees \& C. Mart.) Barroso, in the Irati National Forest, Paraná State, Brazil.

Quando analisada de maneira conjunta, a distribuição espacial de Ocotea odorifera, Nectandra grandiflora e Ocotea porosa, é possível perceber que a maior ocorrência de uma dessas espécies é

FLORESTA, Curitiba, PR, v. 45, n. 4, p. 681 - 694, out. / dez. 2015.

Téo, S. J. et al.

ISSN eletrônico 1982-4688 / ISSN impresso 0015-3826

691

DOI: $10.5380 /$ rf.v45i4.39939 
compensada pela menor ocorrência ou, até mesmo ausência das outras duas espécies de Lauraceae. Este resultado pode ser indicativo de repulsão, ou de grande competição entre essas espécies (Figura 6).

O estudo dos padrões espaciais das diferentes espécies de uma floresta deve levar em conta uma análise sucessional. Os aspectos ecológicos, a biologia reprodutiva e a fenologia das espécies são as características mais citadas para o entendimento das estratégias de estabelecimento e ocupação, mas que estarão sempre restritos, principalmente, aos fatores abióticos, como intensidade de luz, água, temperatura, tipo de solo e disponibilidade de nutrientes (RODE et al., 2010).

Oliveira Filho et al. (2005) utilizaram um SIG como suporte para a espacialização e análise de dados das pesquisas realizadas na FLONA de Irati, em que o banco de dados espacial foi orientado a dois objetos distintos, árvores e parcelas. O geo-objeto árvore foi formado por um polígono fechado que representou a copa da árvore, advindo da fotointerpretação de fotografias aéreas de pequeno formato, dessa forma, sendo possível somente a espacialização das árvores do dossel. Oliveira Filho et al. (2005) recomendaram a utilização de entidades geográficas pontuais para a representação de todas as árvores da área estudada, inclusive aquelas abaixo do dossel da floresta, assim como foi feito neste estudo.

\section{CONCLUSÕES}

- A utilização de SIG permitiu a espacialização do estresse competitivo, do incremento diamétrico dentre outras variáveis em nível de árvore individual e suas combinações, para um fragmento de Floresta Ombrófila Mista.

- A representação espacial do incremento diamétrico das árvores apresentou relação com outras variáveis além do índice de competição, como a área basal dos blocos e estrutura vertical da floresta.

- Tanto o ingresso, como a mortalidade distribuíram-se com relativa homogeneidade pela área da FLONA de Irati. Somente em alguns casos, foi possível identificar a relação de locais com maior mortalidade e estresse competitivo.

- A estrutura espacial e diamétrica da Araucaria angustifolia, representada neste estudo, reforça a teoria de que esta espécie apresenta modelo de regeneração estruturado em coortes.

- A distribuição espacial de Ocotea odorifera, Nectandra grandiflora e Ocotea porosa apresentam-se com indício de repulsão entre essas espécies. Por outro lado, a distribuição espacial da Araucaria angustifolia e Ilex paraguariensis mostrou indicativos de atração.

\section{REFERÊNCIAS}

BOTKIN, D. B.; JANAK, J. F.; WALLIS, J. R. Some ecological consequences of a computer model of forest growth. Journal of Ecology, London, v. 60, n. 3, p. 849 - 872, 1972.

CHASSOT, T.; FLEIG, F. D.; FINGER, C. A. G.; LONGHI, S. J. Modelos de crescimento em diâmetro de árvores individuais de Araucaria angustifolia (Bertol.) Kuntze em Floresta Ombrófila Mista. Ciência Florestal, Santa Maria, v. 21, n. 2, p. 303 - 313, 2011.

DANIELS, R. F.; BURKHART, H. E. Simulation of individual tree growth and stand development in managed loblolly pine plantations. Blacksburg: Virginia Polytechnic Institute and State University, 1975. $69 \mathrm{p}$.

DAVIS, L. S.; JOHNSON, K. N.; BETTINGER, P.; HOWARD, T. E. Forest management: to sustain ecological, economic and social values. 4 ed. Long Grove: Waveland Press, Inc., 2001. 804 p.

DECANINI, M. M. S. SIG no planejamento de trilhas no Parque Estadual de Campos do Jordão. Revista Brasileira de Cartografia, Brasília, n. 53, p. 97 - 110, 2001.

DELLA-FLORA, J. B.; DURLO, M. A.; SPATHELF, P. Modelo de incremento para árvores singulares Nectandra megapotamica (Spreng.) Mez. Ciência Florestal, Santa Maria, v. 14, n. 1, p. 165 - 177, 2004.

DONHA, A. G.; SOUZA, L. C. P.; SUGAMOSTO, M. L. Determinação da fragilidade ambiental utilizando técnicas de suporte à decisão e SIG. Revista Brasileira de Engenharia Agrícola e Ambiental, Campina Grande, v. 10, n. 1, p. 175 - 181, 2006.

EMPRESA BRASILEIRA DE PESQUISA AGROPECUÁRIA (EMBRAPA). (Rio de Janeiro, RJ). Mapa de solos do estado do Paraná. Rio de Janeiro, 2007. Mapa. Escala: 1:600.000. 
FIGUEIREDO FILHO, A.; DIAS, A. N.; STEPKA, T. F.; SAWCZUK, A. R. Crescimento, mortalidade, ingresso e distribuição diamétrica em Floresta Ombrófila Mista. Floresta, Curitiba, v. 40, n. 4, p. 763 776, 2010.

INSTITUTO BRASILEIRO DE GEOGRAFIA E ESTATÍSTICA (IBGE). (Rio de Janeiro, RJ). Atlas Nacional do Brasil: Clima. Rio de Janeiro, 2010 a. Atlas. Escala: 1:15.000.000.

(Rio de Janeiro, RJ). Atlas Nacional do Brasil: Vegetação: cobertura primária. Rio de Janeiro, 2010 b. Atlas. Escala: 1:15.000.000.

KERSTEN, R. A.; GALVÃO, F.; LOPES, O. F. A formação das paisagens paranaenses. Curitiba: Editado pelos autores, 2008. 12 p.

LEITE, P. F. Contribuição ao conhecimento fitoecológico do Sul do Brasil. Ciência \& Ambiente, Santa Maria, n. 24, p. 51 - 73, 2002.

MARTINS, F. B. Modelagem de crescimento em nível de árvore individual para plantios comerciais de eucaliptos. 143 f. Tese (Doutorado em Ciência Florestal) - Universidade Federal de Viçosa, Viçosa, 2011.

MARTINS, F. B.; SOARES, C. P. B.; LEITE, H. G.; SOUZA, A. L. de; CASTRO, R. V. O. Índices de competição em árvores individuais de eucalipto. Pesquisa Agropecuária Brasileira, Brasília, v. 46, n. 9, p. 1089 - 1098, 2011.

OLIVEIRA FILHO, P. C. de; FIGUEIREDO FILHO, A.; KIRCHNER, F. F.; MEDEIROS, J. S. de; OLIVEIRA, E. B. de. Implementação de um Sistema de Informação Geográfica para gestão da empresa florestal. Floresta, Curitiba, v. 33, n. 1, p. 31 - 52, 2003.

OLIVEIRA FILHO, P. C. de; DISPERATI, A. A.; LISBOA, G. S.; VENANCIO, T. L. Um sistema de informações geográficas como suporte a um experimento florestal na FLONA de Irati - PR. In: SIMPÓSIO BRASILEIRO DE SENSORIAMENTO REMOTO, 12., 2005, Goiânia. Anais... Goiânia: Instituto Nacional de Pesquisas Espaciais (INPE), 2005, p. 1637 - 1639.

ORELLANA, E. Sucessão florestal, regimes de manejo e competição avaliados por modelos de árvore individual em um fragmento de Floresta de Araucária. 154 f. Tese (Doutorado em Engenharia Florestal) - Universidade Federal do Paraná, Curitiba, 2014.

PRODAN, M.; PETERS, R.; COX, F.; REAL, P. Mensura Forestal. San José: Instituto Interamericano de Cooperación para la Agricultura (IICA), 1997. 586 p.

RODE, R.; FIGUEIREDO FILHO, A.; MACHADO, S. A.; GALVÃO, F. Análise do padrão espacial de espécies e de grupos florísticos estabelecidos em um povoamento de Araucaria angustifolia e em uma Floresta Ombrófila Mista no Centro-Sul do Paraná. Floresta, Curitiba, v. 40, n. 2, p. 255 - 268, 2010.

RODRIGUES, J. B. T.; ZIMBACK, C. R. L.; PIROLI, E. L. Utilização de Sistema de Informação Geográfica na avaliação do uso da terra em Botucatu (SP). Revista Brasileira de Ciência do Solo, Viçosa, v. 25, n. 3, p. 675 - 681, 2001.

ROIK, M. Dinâmica (2002-2011) e modelagem do incremento diamétrico em fragmento de Floresta Ombrófila Mista na Floresta Nacional de Irati, Paraná. 141 f. Dissertação (Mestrado em Ciências Florestais) - Universidade Estadual do Centro-Oeste, Irati, 2012.

SCOLFORO, J. R. S. Biometria Florestal: modelos de crescimento e produção florestal. Lavras: FAEPE - UFLA, 2006. 393 p.

SOUZA, A. F.; FORGIARINI, C.; LONGHI, S. J.; BRENA, D. A. Regeneration patterns of a long-lived dominant conifer and effects of logging in southern South America. Acta Oecologica, Philadelphia, v. 34, n. 2, p. $221-232,2008$.

WEINER, J. Neighbourhood interference amongst Pinus rigida individuals. Journal of Ecology, London, v. 72, n. 1, p. 183 - 195, 1984.

WEISKITTEL, A. R.; HANN, D. W.; KERSHAW Jr., J. A.; VANCLAY, J. K. Forest growth an yield modeling. Oxford: John Wiley and Sons, 2011. 415 p.

FLORESTA, Curitiba, PR, v. 45, n. 4, p. 681 - 694, out. / dez. 2015.

Téo, S. J. et al.

ISSN eletrônico 1982-4688 / ISSN impresso 0015-3826

693

DOI: $10.5380 /$ rf.v45i4.39939 
FLORESTA, Curitiba, PR, v. 45, n. 4, p. 681 - 694, out. / dez. 2015.

Téo, S. J. et al. 